\title{
Screening for Late Blight Susceptibility in Potato Tubers by Digital Analysis of Cut Tuber Surfaces
}

\author{
Brendan A. Niemira, William W. Kirk, and Jeffrey M. Stein, Department of Botany and Plant Pathology, Michi- \\ gan State University, East Lansing 48824
}

\begin{abstract}
Niemira, B. A., Kirk, W. W., and Stein, J. M. 1999. Screening for late blight susceptibility in potato tubers by digital analysis of cut tuber surfaces. Plant Dis. 83:469-473.

A method for quantification of late blight (Phytophthora infestans) in potato tuber tissue using a digital scanner and image analysis software is presented. The average reflective intensity of light reflected from the cut surface of sample tubers measures the darkened, diseased potato tuber tissue amid lighter, late blight-free tissue. In the absence of disease, potato variety, tuber shape, and tuber size do not influence the scan results. While digital quantification of late blight in tubers under controlled inoculation conditions is consistent, the digital assessments of late blight did not correspond exactly with those from a conventional subjective visual method. Used together, the methods can provide complementary information regarding varietal susceptibility to $P$. infestans development on the tuber surface and internal tuber tissue. The method of image analysis presented may be used to determine susceptibility of potato tubers to late blight in varietal development programs, storage research programs, or other tuber research programs.
\end{abstract}

Late blight (Phytophthora infestans (Mont.) de Bary) has reemerged as a significant threat to potato (Solanum tuberosum L.) production worldwide in recent years $(2,7)$. P. infestans causes severe defoliation and also infects potato tubers after spores or zoospores move through the soil water and penetrate the tuber periderm (4, 12). Severe storage losses can occur after tubers infected with $P$. infestans are held for processing at temperatures above $7{ }^{\circ} \mathrm{C}$ (11). The potato industry in North America has identified as a priority the development of potato varieties with reduced foliar and tuber susceptibility to late blight.

Disease evaluation in plant pathology is often based on visual evaluation of the area of tissue infected $(4,5)$. Visual assessment of disease development relies on assigning a quantitative value, such as an estimated percentage or numeric class designation, to a qualitative visual assessment (e.g., "mild" or "severe") $(9,10)$. Extensive training with the individual disease is necessary for accurate assessment and to ensure that observer bias does not influence this type of evaluation $(1,4)$. Computer-based image analysis of diseased plant material can generate an objective quantitative evaluation.

Qualitative disease rating systems often assess the disease level on the surface of whole tubers or tuber slices $(5,15)$. $P$. infestans darkens blighted tuber tissue, while

Corresponding author: Brendan A. Niemira

E-mail: niemirab@pilot.msu.edu

Accepted for publication 9 February 1999.

Publication no. D-1999-0315-01R

(C) 1999 The American Phytopathological Society healthy tissue remains pale. Extensive late blight infection can lead to infection by secondary pathogens that may change the internal structure of the tuber. The change in the reflective intensity of exposed tuber surfaces can be determined by digital scanning. While digital image analysis in plant pathology is generally associated with determinations of early symptoms of crop diseases on a field level (3), advances in microcomputer and digital optics technology have encouraged the development of image analysis for individual plants or leaves (13). In this study, a digital method of detecting late blight in potato tubers was compared with a method based on visual ratings of whole tubers. The method described in this paper is intended to be used to evaluate the susceptibility of potato tubers to late blight under controlled inoculation conditions.

\section{MATERIALS AND METHODS}

Scan method. The scanned surface was the cut face of an otherwise intact, fresh potato tuber for all experiments, except where noted. Fresh-cut tuber sections were placed cut surface down on a glass plate, $40 \times 30 \mathrm{~cm}$ and $2-\mathrm{mm}$ thick. The glass plate was used to prevent surface contamination of the scanner glass and permitted multiple samples to be prepared and moved to the scanner for image production. The plate was transferred to a flatbed scanner (HP ScanJet 4c; Hewlett-Packard Co., Houston, TX) controlled by an IBM-compatible PC. A 486DX2-80 CPU (Intel Corp., Santa Clara, CA) and a RAM capacity of $32 \mathrm{MB}$ was adequate for the image processing. Scanner control software (DeskScan II version 2.4; Hewlett-Packard Co.) generated an image of the cut tuber surfaces against a black background. The image was formed from light reflected from the cut tuber surfaces.

The brightness value of the image controlled the light intensity of every pixel in the image. The contrast value controlled the differences between light and dark regions of the image. While the scanner control software was able to automatically adjust the brightness and contrast of the image by comparing the relative size of the pale tuber surfaces against the black background, the settings were manually set to 180 units (brightness) and 200 units (contrast) to ensure consistent readings. A photograph-quality image was taken and stored for analysis (Fig. 1). A typical image in tagged image format (.tif) occupies $1 \mathrm{MB}$.

Image analysis: Determination of the average reflective intensity (ARI) of the image of the cut tuber surface. The image files created with the scanner software were loaded into the image analysis software (SigmaScan version 3.0; Jandel Scientific Software, San Rafael, CA). The black background has 0 light intensity units (LIU), while pure white has 255 LIU. Disease-free and blemish-free tuber tissue is pale. Diseased or blemished tuber tissue is darkened. The image of the cut tuber surface was selected for analysis and isolated from the adjacent regions of the image. The image was carefully cropped for irregularly shaped tubers to remove the image of the adjacent tuber skin, and the image of the cut surface was unedited. The area was selected with the "fill" tool, which encompassed all pixels within a given area brighter than the cut-off threshold. The area selection cut-off threshold was set to $10 \mathrm{LIU}$, effectively allowing the software to exclude all parts of the image darker than 10 LIU (e.g., the black background). The ARI of all the pixels within the image gave a measurement of disease severity of the sample.

Sample preparation methodology. Potato tubers were stored in the dark at $3{ }^{\circ} \mathrm{C}$ for 6 months after harvest in 1996. Potato tuber surfaces were cut smooth by passing the tubers through a rotating-blade slicer (model 1042; Rival Co., Sedalia, MO). Tuber sections were of uniform thickness (3 mm), except where noted. Sample size for each treatment varied from 9 to 76 .

Disease-free tubers were used to determine the impact of tuber slice thickness, size, and shape on the ARI. The average intensities of small $(<20,000$ pixels) images were compared with the average intensities of large ( $>20,000$ pixels) images of cut 
surfaces of healthy tubers ('Atlantic'). Cut surfaces of healthy tubers ('Atlantic', 'Superior', and 'Russet Burbank') were compared to evaluate differences from potato type and flesh color. The ARI of the image of the cut tuber surface was measured.

Tubers ('Atlantic') were cut transversely along the vascular axis and compared with longitudinal surfaces cut across the vascular axis. The ARI of the image of cut tuber surfaces was measured. The ARI of the image of the tuber surface ('Atlantic') cut across the longitudinal axis of the tuber of different thicknesses was evaluated. Tuber sections ('Atlantic') of uniform thickness $(3 \mathrm{~mm})$ were cut into a variety of shapes to evaluate possible effects resulting from scans of objects with sharp edges. Tubers were cut into semicircles, quarter-circles, rectangles, and acute triangles. These pieces were scanned, and the ARI of the image of the cut tuber surface was measured.

Potato tubers infected with late blight are susceptible to secondary infections such as soft rot (Erwinia carotovora), which change the physical structure of the tuber but may not result in darkening of the affected tissue. Surface treatments such as free water and altered surface topography were used to simulate the effect of this type of secondary infection. The surfaces of 'Atlantic' tuber sections cut longitudinally were scanned immediately after cutting or were dipped in distilled water for $1 \mathrm{~s}$ and scanned. The effect of surface topography was evaluated by rotation of a sharp knife point in the surface of the otherwise smooth cut surfaces, resulting in rough conical depressions approximately 4-mm deep. The gouged samples were scanned fresh and after dipping in water. The ARIs of the cut surfaces were compared using analysis of variance (ANOVA). The treatments were compared within each factor examined.

Digital evaluation of tubers infected with $P$. infestans. The digital assessment technique was tested on tubers inoculated with $P$. infestans. Tubers of the commercial

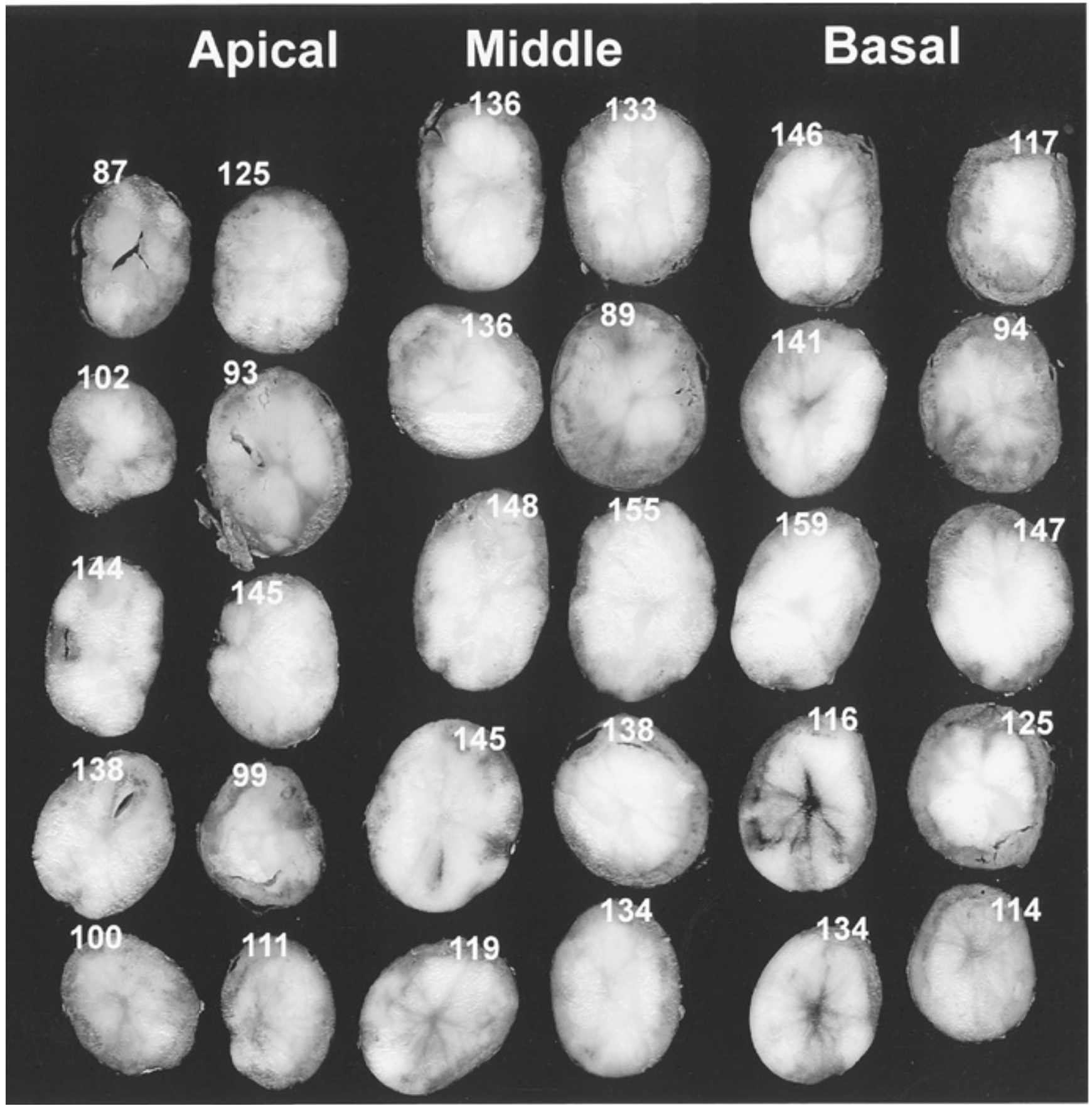

Fig. 1. Digital image of apical, middle, and basal sections from 'MSB076-2' tubers inoculated with Phytophthora infestans. Numbers indicate average reflective intensity (ARI) for each tuber surface, expressed in light intensity units (LIU). 
varieties Atlantic, Snowden, and Yukon Gold and of the advanced potato breeding lines MSB073-2, MSB076-2, MSE202-3 Rus, MSG007-1, MSG050-2, MSG141-3, and MSG274-3 were obtained from the Michigan State University potato breeding program (D. Douches, Department of Crop and Soil Science, MSU). These varieties were selected for their range of susceptibility to late blight (6). Ten tubers from each variety were surface-sterilized by soaking in a $10 \%$ bleach solution for $30 \mathrm{~min}$ and rinsed five times with distilled water.

Tubers were inoculated with $P$. infestans isolate PAI 97-1, US8, A2 mating type as determined by the method of Goodwin et al. (8). Pure cultures of $P$. infestans (PAI 97-1) were grown on rye agar plates for 14 days at $18^{\circ} \mathrm{C}$ in the dark, and then transferred to the light for 2 days to encourage sporulation. A mycelial homogenate was prepared from the mature culture (14). Approximately $0.1 \mathrm{ml}$ was injected into the apical end of the surfacesterilized tuber. The homogenate was injected 3 to $5 \mathrm{~mm}$ into the tuber periderm, adjacent to the apical meristem. Tubers were held in the dark at $12^{\circ} \mathrm{C}$ and $95 \%$ relative humidity for 40 days. The inoculated tubers were removed from storage, and disease was rated visually. The 1-to-9 scale used (Table 1) relies on the surface disease development characteristics of late blight. The tubers were evaluated first for skin discoloration. If the critical threshold of greater than $10 \%$ discoloration was reached, sprout damage was assessed. If more than five damaged sprouts were evident, fungal sporulation was assessed. If sporulation was evident on greater than $10 \%$ of the surface area, the physical degradation of the tuber was assessed. The surface features described correspond to increasing severity in late blight. In cases in which a more severe indicator (e.g., extensive physical degradation) was obtained before a critical threshold of a less severe indicator (e.g., five sprouts damaged), the higher rating was assigned to the tuber. Each tuber was assessed for each of these characteristics and the appropriate numerical rating assigned. The tubers were then cut

Table 1. Visual rating scale for late blight (Phytophthora infestans) disease symptoms in whole potato tubers

\begin{tabular}{lcccc}
\hline Rating & $\begin{array}{c}\text { Skin discoloration } \\
\text { (\% of surface) }\end{array}$ & $\begin{array}{c}\text { Sprout damage } \\
\text { (\# total sprouts) }\end{array}$ & $\begin{array}{c}\text { Sporulation } \\
\text { (\% of surface) }\end{array}$ & $\begin{array}{c}\text { Physical degradation } \\
\text { (\% of surface) }\end{array}$ \\
\hline 1 & 0 & 0 & 0 & 0 \\
2 & $>10$ & 0 & 0 & 0 \\
3 & $>10$ & $0-5$ & 0 & 0 \\
4 & $>25$ & $>5$ & $<10$ & 0 \\
5 & $>25$ & $>5$ & $10-50$ & $<10($ areas $<1 \mathrm{~cm})$ \\
6 & $>25$ & $>5$ & $50-75$ & $10-25($ areas $>1 \mathrm{~cm})$ \\
7 & $>25$ & $>5$ & $>75$ & $25-50($ areas $>1 \mathrm{~cm})$ \\
8 & $>25$ & $>5$ & $>75$ & $50-75$, loss of internal structure \\
9 & $>25$ & $>5$ & $>75$ & $75-100$, complete physical breakdown \\
\hline
\end{tabular}

into four equal sections, exposing the apical, middle, and basal regions of the tuber flesh. These interior surfaces were digitally scanned (Fig. 1) and analyzed. In a second run of the study, evaluations were repeated with the same varieties.

The ARI (simple ARI) was measured in sections from the apical, middle, and basal regions of the tuber, approximately 25,50 , and $75 \%$ of the length of the tuber, respectively, as measured from the apical end. A single value (mean ARI) was generated for each tuber from the mean of the ARIs of the apical, middle, and basal sections.

For diseased tubers, the assessments for each variety were compared with one-way ANOVA within each simple ARI and the mean ARI. The three simple ARIs (apical, middle, and basal) for each individual variety were compared using one-way ANOVA. The digital assessments of internal disease were compared with the visual assessment of external disease by Pearson product moment correlation analysis.

\section{RESULTS}

Comparison of ARI in disease-free cut tuber surfaces. The size of the image area scanned had no significant effect on the ARI of the cut tuber surface (Table 2). Orientation of the tuber had no significant effect on the average intensity of the cut tuber surface (Table 2). Removal of the vascular ring from the images had no significant effect for either the transverse or longitudinal orientation, although the cropped images significantly differed from each other. The ARI increased with section thickness (Table 2). For sections of 3 and $4 \mathrm{~mm}$, the difference in the ARI was not statis-

Table 2. Influence of potato variety and sample preparation on average reflective intensity of healthy tuber tissue

\begin{tabular}{|c|c|c|c|c|c|}
\hline Factor & Treatment & Sample size & $\operatorname{ARI}(\mathbf{L I U})^{\mathrm{x}}$ & Standard error & $P<0.05^{\mathrm{y}}$ \\
\hline Tuber size & $\begin{array}{l}\text { Small }(<20,000 \text { pixels }) \\
\text { Large }(>20,000 \text { pixels })\end{array}$ & $\begin{array}{r}9 \\
11\end{array}$ & $\begin{array}{l}217.0 \\
215.9\end{array}$ & $\begin{array}{l}2.55 \\
0.72\end{array}$ & $\begin{array}{l}\mathrm{a} \\
\mathrm{a}\end{array}$ \\
\hline Tuber variety & $\begin{array}{l}\text { 'Atlantic' } \\
\text { 'Superior' } \\
\text { 'Russet Burbank' }\end{array}$ & $\begin{array}{l}11 \\
11 \\
10\end{array}$ & $\begin{array}{l}239.4 \\
239.4 \\
242.8\end{array}$ & $\begin{array}{l}0.75 \\
0.76 \\
1.51\end{array}$ & $\begin{array}{l}\mathrm{a} \\
\mathrm{a} \\
\mathrm{a}\end{array}$ \\
\hline Orientation along axis & $\begin{array}{l}\text { Transverse } \\
\text { Longitudinal } \\
\text { Transverse cropped image } \\
\text { Longitudinal cropped image }\end{array}$ & $\begin{array}{l}18 \\
16 \\
18 \\
16\end{array}$ & $\begin{array}{l}240.7 \\
238.2 \\
239.2 \\
235.2\end{array}$ & $\begin{array}{l}1.10 \\
1.10 \\
1.00 \\
0.92\end{array}$ & $\begin{array}{c}\mathrm{a} \\
\mathrm{ab} \\
\mathrm{a} \\
\mathrm{b}\end{array}$ \\
\hline Section thickness & $\begin{array}{l}1 \mathrm{~mm} \\
2 \mathrm{~mm} \\
3 \mathrm{~mm} \\
4 \mathrm{~mm} \\
5 \mathrm{~mm} \\
6 \mathrm{~mm}\end{array}$ & $\begin{array}{l}12 \\
12 \\
12 \\
12 \\
12 \\
12\end{array}$ & $\begin{array}{l}170.2 \\
219.5 \\
232.1 \\
234.1 \\
238.7 \\
242.7\end{array}$ & $\begin{array}{l}1.23 \\
0.85 \\
1.12 \\
0.99 \\
1.31 \\
0.51\end{array}$ & $\begin{array}{l}\mathrm{a} \\
\mathrm{b} \\
\mathrm{c} \\
\mathrm{c} \\
\mathrm{d} \\
\mathrm{d}\end{array}$ \\
\hline Section shape & $\begin{array}{l}\text { Semicircle } \\
\text { Quarter-circle } \\
\text { Rectangle } \\
\text { Triangle }\end{array}$ & $\begin{array}{l}49 \\
63 \\
38 \\
76\end{array}$ & $\begin{array}{l}210.0 \\
210.1 \\
205.6 \\
199.5\end{array}$ & $\begin{array}{l}1.09 \\
0.56 \\
1.23 \\
0.92\end{array}$ & $\begin{array}{l}\mathrm{a} \\
\mathrm{a} \\
\mathrm{b} \\
\mathrm{b}\end{array}$ \\
\hline Tuber surface & $\begin{array}{l}\text { Dry } \\
\text { Dry, pitted } \\
\text { Wet } \\
\text { Wet, pitted }\end{array}$ & $\begin{array}{l}11 \\
11 \\
11 \\
11\end{array}$ & $\begin{array}{l}243.2 \\
234.6 \\
238.2 \\
229.5\end{array}$ & $\begin{array}{l}0.82 \\
1.46 \\
0.74 \\
1.02\end{array}$ & $\begin{array}{l}\mathrm{a} \\
\mathrm{b} \\
\mathrm{b} \\
\mathrm{c}\end{array}$ \\
\hline
\end{tabular}

${ }^{\mathrm{x}}$ Average reflective intensity (ARI) in light intensity units (LIU).

y Treatments within a given factor with different letters are significantly different by analysis of variance $(P<0.05)$.

${ }^{\mathrm{z}}$ Image cropped to remove vascular ring from analysis. 
tically significant. Sections 5- and 6-mm thick were significantly different in comparison with thinner sections, but not from each other. Shapes with straight edges and corners (rectangles and triangles) generally had a lower ARI than did shapes with curved edges (semicircles and quarter-circles) (Table 2). Altered surface topography and the presence of free liquid affected the ARI of the cut slices of tubers (Table 1). Sections with pitted surfaces had a significantly lower ARI than did smooth cut tuber surfaces (232.0 and 240.7 LIU, respectively). Tuber section surfaces with free liquid had a significantly lower ARI than did surfaces without free liquid (233.8 and 238.9 LIU, respectively).

Comparison of disease assessment methods in tubers infected with $P$. infestans. In the first run of the study involving diseased tubers, the visual and digital disease assessment methods were each able to distinguish between varieties with differing susceptibility (Table 3 ). The ARI from each tuber region, as well as the average ARI, was significantly $(P<0.001)$ correlated with the visual assessment. Typical ARI values are shown on Figure 1. Rankings for disease severity (most susceptible to least susceptible) were similar for visual and digital methods in 8 of the 10 varieties examined, except 'MSG141-3' and 'MSG274-3'. Correlation coefficients for visual assessments with each ARI (apical, middle, basal, and mean) ranged from -0.38 to -0.58 (Table 3). For 6 of the 10 varieties examined, ARI values differed significantly among tuber sections $(P<0.05)$, with the ARI generally increasing with distance from the inoculation site.

In the second run of the study involving diseased tubers, the overall level of disease observed was less than in the first run (Table 3). As in the first run, visual and digital disease assessment methods were each able to distinguish between varieties with differing susceptibility. The ARI from each tuber region, as well as the average ARI, was significantly $(P<0.001)$ correlated with the visual assessment. The correlation coefficients for the second run tended to be greater in magnitude than those of the first run. Correlation coefficients for visual assessments with each ARI (apical, middle, basal, and mean) ranged from -0.60 to -0.65 (Table 3) Rankings for disease severity (most susceptible to least susceptible) were similar for visual and digital methods in 7 of the 10 varieties examined, except 'MSG141-3', 'MSG274-3', and 'Yukon Gold'. For 2 of the 10 varieties examined, ARI values differed significantly among tuber sections $(P<0.05)$, with the ARI generally increasing with distance from the inoculation site.

\section{DISCUSSION}

Consistency of sample preparation was an essential element in the scanning method. ARIs of healthy tubers tended to be insensitive to differences between variety and tuber size; however, different tuber orienta- tions, section thicknesses, and shapes resulted in significant, though small, differences. Thinner tuber sections may allow greater transmission of light through the section, thereby reducing the light reflected from the section surface. This would return a lower (darker) ARI rating than sections that reflect light more effectively. Abrasion and wetting of the tuber surface also resulted in significantly different ARIs. Opportunistic secondary pathogens such as soft rot (E. carotovora), which can produce this type of physical degradation (1), may therefore interfere with the digital assessment. These results suggest that the method may best be used under controlled inoculation conditions, in which the possibility of development of secondary pathogens is low.

The visual assessment was made of disease symptoms on the tuber surface, while the digital assessments were made from regions within the tuber tissue. The visual method relies on development of the fungus on the surface (extent of sporulation) as well as in the subsurface (discoloration and physical degradation). The digital method relies on internal discoloration and physical degradation. This comparison between a common nondestructive visual rating system with the destructive digital method shows the potential for using both methods together. Visual rating of tuber surfaces was rapid and required no equipment. Computerized image generation and analysis was labor intensive and required specialized equipment. Image analysis is

Table 3. Visual and digital evaluation of late blight susceptibility in breeding lines and commercial potato varieties

\begin{tabular}{|c|c|c|c|c|c|c|}
\hline Variety & Visual rating & Apical ARI & Middle ARI & Basal ARI & Difference between sections & Average ARI \\
\hline \multicolumn{7}{|l|}{ Run \#1 } \\
\hline Atlantic & $4.5 \mathrm{~d}^{\mathrm{w}}$ & $135 a b c^{x}$ & $163 \mathrm{ab}$ & $159 \mathrm{bc}$ & $P<0.05$ & $152 \mathrm{bc}$ \\
\hline MSB073-2 & $5.4 \mathrm{c}$ & $129 \mathrm{bc}$ & $149 \mathrm{~b}$ & $149 \mathrm{bcd}$ & $P<0.05$ & $142 \mathrm{c}$ \\
\hline MSB076-2 & $6.2 \mathrm{~b}$ & $115 \mathrm{c}$ & $133 \mathrm{c}$ & $129 \mathrm{~d}$ & $\mathrm{NS}^{\mathrm{y}}$ & $126 \mathrm{e}$ \\
\hline MSE202-3 Rus & $3.9 \mathrm{~d}$ & $162 \mathrm{a}$ & $178 \mathrm{a}$ & $190 \mathrm{a}$ & $P<0.05$ & $177 \mathrm{a}$ \\
\hline MSG007-1 & $5.1 \mathrm{c}$ & $140 \mathrm{abc}$ & $157 \mathrm{~b}$ & $156 b c$ & NS & $151 \mathrm{bc}$ \\
\hline MSG050-2 & $7.1 \mathrm{a}$ & $136 b c$ & $132 \mathrm{c}$ & $139 \mathrm{~cd}$ & NS & $135 \mathrm{~d}$ \\
\hline MSG141-3 & $7.2 \mathrm{a}$ & $130 \mathrm{bc}$ & $154 \mathrm{~b}$ & $172 \mathrm{ab}$ & $P<0.05$ & $152 \mathrm{bc}$ \\
\hline MSG274-3 & $3.9 \mathrm{~d}$ & $128 \mathrm{bc}$ & $153 \mathrm{~b}$ & $155 \mathrm{bc}$ & $P<0.05$ & $145 \mathrm{c}$ \\
\hline Snowden & $4.3 \mathrm{~d}$ & $147 \mathrm{ab}$ & $159 \mathrm{~b}$ & $167 \mathrm{ab}$ & NS & $158 \mathrm{bc}$ \\
\hline Yukon gold & $4.3 \mathrm{~d}$ & $144 \mathrm{ab}$ & $166 \mathrm{ab}$ & $173 \mathrm{ab}$ & $P<0.05$ & $161 \mathrm{~b}$ \\
\hline Correlation coefficient ${ }^{\mathrm{z}}$ & & -0.38 & -0.58 & -0.39 & & -0.51 \\
\hline Significance & & $P<0.001$ & $P<0.001$ & $P<0.001$ & & $P<0.001$ \\
\hline \multicolumn{7}{|l|}{ Run \#2 } \\
\hline Atlantic & $3.5 \mathrm{~b}$ & $182 \mathrm{a}$ & $187 \mathrm{a}$ & $186 \mathrm{a}$ & NS & $185 \mathrm{a}$ \\
\hline B073-2 & $3.7 \mathrm{~b}$ & $171 \mathrm{a}$ & $183 a b$ & $183 \mathrm{a}$ & NS & $179 a b$ \\
\hline B076-2 & $5.3 \mathrm{a}$ & $121 \mathrm{c}$ & $142 \mathrm{c}$ & $143 \mathrm{c}$ & NS & $135 \mathrm{c}$ \\
\hline E202-3 Rus & $3.9 \mathrm{~b}$ & $160 \mathrm{ab}$ & $176 a b$ & $184 \mathrm{a}$ & $P<0.05$ & $173 a b$ \\
\hline G007-1 & $3.6 \mathrm{~b}$ & $164 \mathrm{a}$ & $176 \mathrm{ab}$ & $183 \mathrm{a}$ & NS & $174 \mathrm{ab}$ \\
\hline G050-2 & $5.6 \mathrm{a}$ & $132 \mathrm{bc}$ & $141 \mathrm{c}$ & $150 \mathrm{c}$ & NS & $141 \mathrm{c}$ \\
\hline G141-3 & $5.4 \mathrm{a}$ & $154 \mathrm{ab}$ & $172 a b$ & $183 \mathrm{a}$ & $P<0.05$ & $170 \mathrm{ab}$ \\
\hline G274-3 & $2.9 \mathrm{c}$ & $179 a$ & $180 \mathrm{ab}$ & $181 \mathrm{a}$ & NS & $180 \mathrm{ab}$ \\
\hline Snowden & $3.9 \mathrm{~b}$ & $151 \mathrm{ab}$ & $165 \mathrm{~b}$ & $171 \mathrm{~b}$ & NS & $163 \mathrm{~b}$ \\
\hline Yukon Gold & $3.6 \mathrm{~b}$ & $153 \mathrm{ab}$ & $167 \mathrm{ab}$ & $170 \mathrm{~b}$ & NS & $163 \mathrm{~b}$ \\
\hline Correlation coefficient ${ }^{\mathrm{z}}$ & & -0.62 & -0.60 & -0.53 & & -0.65 \\
\hline Significance & & $P<0.001$ & $P<0.001$ & $P<0.001$ & & $P<0.001$ \\
\hline
\end{tabular}

${ }^{v}$ Average reflective intensity (ARI) in light intensity units (LIU).

${ }^{\mathrm{w}}$ Treatments within a given factor with different letters are significantly different by analysis of variance $(P<0.05)$.

${ }^{x}$ Lower ARI value $=$ darker tissue $=$ more disease.

${ }^{y}$ The section ARIs of varieties marked NS were not significantly different from each other.

${ }^{\mathrm{z}}$ Correlation (Pearson rank order) with conventional visual assessment. 
quantitative and objective. The scanned images can be stored for future comparisons. The visual and digital disease assessment methods presented were able to separate varieties based on susceptibility to $P$. infestans. The digital method tended to rank 'MSG141-3' and 'Yukon Gold' (in run 2) as less susceptible than indicated by the visual method, while the opposite was true for 'MSG274-3'. This suggests that in 'MSG141-3' and 'Yukon Gold' surface and subsurface development of $P$. infestans is notably more extensive than internal fungal development. The opposite may be concluded for 'MSG274-3'.

The tubers showed generally increasing ARIs (decreasing disease severity) with increasing distance from the apical site of inoculation. This effect was variety dependent and was more pronounced in the first run of the experiment, which had generally higher levels of disease than the second run. The sampling from different areas within the tuber may potentially provide information of the comparative speed with which the disease progresses through tuber tissue of different varieties. This can inform breeding and selection programs as to the relative susceptibility of advanced breeding lines. Also, the aggressiveness of isolates of $P$. infestans in commercial varieties could be objectively determined with this method. The results from the digital methods were generally correlated with those of the visual method, with correlation coefficients ranging from -0.38 to -0.65 in both runs. These values suggest that the digital method, which measures internal disease development, and the visual method, which measures surface disease development, can lead to somewhat different assessments of a given variety's overall susceptibility. As there are currently no late blight-resistant potato varieties commercially available (6), breeding programs have made the development of late blight resis- tance a priority. While each of the methods have advantages and disadvantages, the use of both methods in a complementary manner can provide a greater understanding of the nature of a given variety's susceptibility.

The digital analysis method uses commonly available computer technology to make quantitative measurements of $P$. infestans in potato that are consistent and reproducible. The necessity of uniform inoculation indicates that this method may best be used under controlled inoculation conditions, rather than for analysis of naturally infected tuber material. This method may be applied in breeding programs with tubers harvested from foliar crop protectant programs or with tubers from experimental temperature storage regimes. Digital disease evaluation can be a valuable tool in researching tuber susceptibility to late blight by increasing the depth of understanding of how a given variety responds to inoculation, both on the surface and internally.

\section{ACKNOWLEDGMENTS}

This work was funded, in part, by the Michigan Agricultural Experiment Station and by a grant from the Agriculture in Concert with the Environment (ACE) program, a jointly funded USEPA/USDA Co-operative State Research, Education and Extension Service program (cooperative agreement no. 94-COOP-1-0809). We thank A. Jarosz and D. Douches for their reviews of this manuscript and K. Mason for technical assistance.

\section{LITERATURE CITED}

1. Agrios, G. N. 1988. Introduction to plant pathology. Pages 3-40 in: Plant Pathology, 3rd ed. Academic Press, San Diego, CA.

2. Andviron, R. 1995. Comparison of race structure and diversity in populations of Phytophthora infestans, 1966-1993. Pages 71-76 in: Phytophthora infestans 150. L. J. Dowley, E. Bannon, L. R. Cooke, T. Keane, and E. O. Sullivan, eds. Boole Press, Dublin.

3. Blazquez, C. H. 1990. Late blight detection in tomato fields by aerial photography with natural and infrared color film. Plant Dis. 74: 589-592.
4. Campbell, C. L., and Madden, L. V. 1989 Monitoring epidemics: Disease. Pages 107128 in: Introduction to Plant Disease Epidemiology. John Wiley \& Sons, New York.

5. Dorrance, A. E., and Inglis, D. A. 1998. Assessment of laboratory methods for evaluating potato tubers for resistance to late blight. Plant Dis. 82:442-446.

6. Douches, D. S., Kirk, W. W., Jastrzebski, K., Long, C., and Hammerschmidt, R. 1997. Susceptibility of potato varieties and advanced breeding lines (Solanum tuberosum L.) to Phytophthora infestans (Mont.) de Bary in greenhouse screenings. Am. Potato J. 74:75-86.

7. Fry, W. E., and Goodwin, S. B. 1995. Recent migrations of Phytophthora infestans. Pages 89-95 in: Phytophthora infestans 150. L. J. Dowley, E. Bannon, L. R. Cooke, T. Keane, and E. O. Sullivan, eds. Boole Press, Dublin.

8. Goodwin, S. B., Schneider, R. E., and Fry, W 1995. Use of cellulose-acetate electrophoresis for rapid identification of allozyme genotypes of Phytophthora infestans. Plant Dis. 79:11811185 .

9. Horsfall, J. G., and Barratt, R. W. 1945. An improved grading system for measuring plant diseases. (Abstr.) Phytopathology 35:655.

10. James, W. C. 1971. A Manual of Assessment Keys for Plant Diseases. The American Phytopathological Society, St. Paul, MN.

11. Kirk, W. W., Niemira, B. A., Kitchen, B., Stein, J. M., and Hammerschmidt, R. 1997. Digital assessment of late blight (Phytophthora infestans) in tubers of three susceptible varieties as influenced by storage temperature. Page 9 in: Proc. Annu. Meeting Potato Assoc. Am., 81st. Potato Association of America, Orono, ME.

12. Lacey, J. 1977. The role of water in the spread of Phytophthora infestans in the potato crop. Ann. Appl. Biol. 59:245-255.

13. Martin, D. P., and Rybicki, E. P. 1998. Microcomputer-based quantification of maize streak virus symptoms in Zea mays. Phytopathology 88:422-427.

14. Schmitthenner, A. F., and Bhat, R. G. 1994. Simple pathogenicity tests. Pages 6-7 in: Useful Methods for Studying Phytophthora in the Laboratory. Ohio Agricultural Research and Development Center, Ohio State University, Wooster.

15. Stewart, H. E., Wastie, R. L., and Bradshaw, J. E. 1996. Susceptibility of field and glasshouse grown potato tubers. Potato Res. 39: 283-288. 